Revista de Ensino em Artes, Moda e Design

Dossiê 5

As fontes de pesquisa para moda. Uma aproximação interdisciplinar e arquivista da história da moda: pesquisa e ensino.

\title{
DOCUMENTAÇÃO DE COLEÇÕES MUSEOLÓGICAS DE VESTUÁRIO: CLASSIFICANDO UMA ROUPA HÍBRIDA NA COLEÇÃO AMAZONIANA DE ARTE DA UFPA
}

Museum documentation of costume collections: classifying a hybrid garment from UFPA's amazoniana art collection

\section{Documentation de collections museologiques de vêtements: classement d'un vêtement hybride dans la Collection d'Art Amazonienne de l'Université Fédérale du Para}

\author{
Susanne Pinheiro Dias ${ }^{1}$ \\ Mariano Klautau ${ }^{2}$
}

\footnotetext{
1 Mestra em Comunicação, Linguagens e Cultura (Universidade da Amazônia). Bacharel em Moda (Universidade da Amazônia). E-mail: susannepinheiro@gmail.com | Lattes: http://lattes.cnpq.br/6122062740937223 | Orcid: http://orcid.org/0000-0001-6091-9623
} 


\section{Resumo}

Tomando como base as ações de documentação dos objetos da Seção Moda da Coleção Amazoniana de Arte da Universidade Federal do Pará, este artigo objetiva discutir e propor alternativas de classificação de uma peça de vestuário de autoria da marca brasileira 'André Lima'. Ao misturar as estruturas de vestuário aberto (próprio das saias e vestidos) e fechado (próprio de calças, bermudas, calcinhas etc.), tal objeto desestabiliza uma lógica classificatória que pressupõe categorias e nomenclaturas estáveis para cada item pertencente a uma coleção. Como identificá-lo em termos museológicos? Para pensar essa questão, buscamos, primeiramente, relacionar os principais aspectos que envolvem a documentação museológica de objetos de vestuário. Em um segundo momento, apresentamos os processos de documentação dessa tipologia de objeto na Coleção Amazoniana de Arte da UFPA. Por fim, desenvolvemos uma análise da peça a partir do método interpretativo de objetos de moda concebido por Mida e Kim (2015). Mais do que atender a uma demanda interna da coleção em questão, o estudo desse objeto reflete particularidades da gestão de acervos de moda no Brasil, além de apontar chaves de compreensão do pensamento criativo do estilista André Lima e da moda contemporânea brasileira.

Palavras-Chave: Documentação museológica. Moda contemporânea. André Lima

\section{Abstract}

Based on documentation practices adopted by the Fashion section of UFPA's Amazoniana Art Collection, this article aims to discuss and propose alternatives for the classification of an article of clothing by the Brazilian fashion brand 'André Lima'. By mixing clothing structures that are both open (such as skirts and dresses) and closed (pants, shorts, panties etc.), this object destabilizes a classification logic that assumes infallible categories and nomenclatures for each item of a collection. What should it be called in museological terms? To answer this question, we first sought to relate the main aspects that are involved in the museological documentation of clothing. Next, we explained UFPA's Amazoniana Art Collection documentation practices for this type of object. Finally, we developed an analysis of the piece using the interpretive method of fashion objects developed by Mida and Kim (2015). Besides meeting an internal demand by the collection in question, the study of this object reflects the particularities of managing fashion collections in Brazil. Also, it points out keys to understanding the creative thinking of the designer André Lima and contemporary fashion in Brazil.

Key-words: Museum documentation. Contemporary fashion. André Lima.

\section{Resumé}

En partant des actions de documentation des objets de la section de Mode de la Collection d'Art Amazonienne de l'Université Fédérale du Para, cet article propose à la fois une discussion sur une pièce de vêtement créée par la marque brésilienne 'André Lima' et une mise en revue des possibilités pour la classer. Lorsque l'on mélange les structures de vêtements ouverts (des jupes et des robes, par exemple) aux structures de vêtements fermés (des pantalons, des shorts, des culottes etc.), on déstabilise la logique de classification qui suppose des catégories et des nomenclatures stables pour chaque article d'une collection. Comment classer ces articles dans un cadre muséologique? Pour réfléchir à cette question, il nous faut d'abord mettre en relation les aspects majeurs de la documentation muséologique des objets vestimentaires. Ensuite, il sera temps de présenter le processus de documentation de la typologie d'objets dans la Collection d'Art Amazonienne de l'UFPA. Nous procéderons enfin à une analyse de la pièce en question à travers l'interprétation d'objets de mode, une méthode conçue par Mida et Kim (2015). Plus que répondre à une demande interne de la collection en question, cette étude reflète les particularités de la gestion des collections de mode au Brésil. Elle offre également des outils pour la compréhension de la pensée créatrice du designer André Lima ainsi que de la mode contemporaine brésilienne.

Mots-clés: Documentation muséologique. Mode contemporaine. André Lima. 


\section{INTRODUÇÃO}

O presente artigo apresenta um recorte da dissertação Documentação museológica de moda contemporânea: catalogação de roupas desobedientes de André Lima na Coleção Amazoniana de Arte da UFPA ${ }^{1}$. Considerando o controle terminológico como um dos eixos norteadores da documentação museológica, a pesquisa teve como objetivo principal analisar e propor alternativas de classificação de três objetos de vestuário pertencentes a Seção Moda da Coleção Amazoniana de Arte da UFPA. Ao sugerirem múltiplas funções, estarem inacabados e/ou apresentarem uma estrutura híbrida, tais objetos embaralhavam uma lógica de classificação arbórea, recusando categorias e nomenclaturas estáveis. Como nomeá-los em termos museológicos? Nesse recorte, compartilhamos a análise e o processo de classificação do objeto registrado na referida coleção como 'RTM.AL.I.17'.

Eram meados de 2015 quando tive o primeiro contato com o acervo da Seção Moda da Amazoniana. Havia sido convidada para atuar como colaboradora no projeto de extensão "Ações de curadoria de acervo na Seção Moda da Coleção Amazoniana de Arte da UFPA". Depositado em uma das reservas técnicas da Faculdade de Artes Visuais da Universidade Federal do Pará, o acervo encontrava-se em processo de arrolamento. Cerca de um ano antes, o estilista paraense André Lima havia fechado seu ateliê na cidade de São Paulo e doado uma amostra considerável dos objetos abrigados em seu espaço de criação para a Amazoniana. Com a doação, a coleção universitária, voltada originalmente para a arte contemporânea na/sobre Amazônia, abria, em 2015, uma seção dedicada a moda.

A cada caixa aberta durante o processo de arrolamento, a sensação era a de estar adentrando os universos "sampleados, dramáticos, místicos, selvagens, sofisticados, femininos e às vezes andróginos" (SOUZA, 2013, p. 9) concebidos por um dos estilistas mais conhecidos da moda contemporânea brasileira. Entre cartelas de cores, fichas técnicas, vestidos com metros e metros de tecido, brincos gigantes, fui fisgada pelo objeto 'RTM.AL.I.17'. A peça provocava questionamentos quanto à sua identificação ao apresentar uma estrutura de construção que combinava os sistemas aberto (próprio de saias e vestidos) e fechado (próprio de calças, shorts, calcinhas etc.). Não havia nenhum termo que a descrevesse na publicação Termos básicos para a catalogação de vestuário (ICOM COSTUME/BENARUSH, 2014), adotada como base terminológica dos objetos de vestuário e acessórios da Seção Moda. Como classificá-la?

Para pensar essa questão, dividimos o artigo em três partes. Primeiramente, buscamos delinear os principais aspectos que envolvem a documentação museológica de coleções de vestuário. Em um segundo momento, expomos as ações de documentação voltadas para objetos de vestuário na Seção Moda da Amazoniana. Por fim, analisamos as características intrínsecas e extrínsecas do objeto 'RTM.AL.I.17' para que, com base nisso, apontemos possibilidades de classificação da peça que atendam tanto a lógica documental da Seção Moda quanto aos conceitos e narrativas engendradas pelo estilista André Lima em seu processo criativo.

Em termos metodológicos, o estudo do objeto é guiado pelo método interpretativo de objetos de moda idealizado por Mida e Kim (2015). Entendendo que um objeto de

\footnotetext{
1 A pesquisa foi desenvolvida no Programa de Pós-graduação em Comunicação, Linguagens e Cultura da Universidade da Amazônia, sob orientação do Prof.Dr. Mariano Klautau. Foi defendida em 2018.
} 
vestuário carrega tanto aspectos materiais quanto simbólicos que - quando vistos em contexto - apontam para narrativas pessoais e culturais de um tempo, tal método apresenta três estágios de análise: 1. Observação; 2. Reflexão; 3. Interpretação.

O primeiro estágio compreende a observação e a descrição detalhada dos elementos construtivos da peça, dos materiais empregados, das cores, medidas, assim como a verificação de etiquetas, outros documentos relacionados a peça, marcas de desgaste e/ou alterações tais como manchas, puimentos e recosturas.

Já a fase da reflexão enfoca a experiência sensível e singular do sujeito-pesquisador diante do objeto estudado. O objeto apresenta alguma imagem? Faz barulho? É pesado? É brilhoso? Tem cheiro? Que tipo de sensações o objeto provoca? Esse estágio também inclui a compilação e análise de outras fontes relacionadas ao objeto em si, ao criador/fabricante e/ou ao dono, tais como peças semelhantes, fotografias, ilustrações, vídeos, revistas, artigos acadêmicos etc ${ }^{2}$.

Por fim, o terceiro estágio consiste no cruzamento e na síntese dos dados levantados pelo pesquisador nas etapas anteriores com as teorias, propósitos e perguntas da investigação. O que há de diferente no objeto analisado? A que tipos de tendências estético-culturais ele se conecta? Trata-se, nesse momento, do exercício de interpretação dos resultados, ou seja, da articulação da experiência empírica com os horizontes teóricos e as informações obtidas durante todo o processo de análise do objeto.

\section{DOCUMENTAÇÃO MUSEOLÓGICA DE COLEÇÕES DE VESTUÁRIO: CON- SIDERAÇÕES BÁSICAS}

Todo objeto, ao ser musealizado, passa a ser visto "em função de seu potencial de testemunho, ou seja, pela qualidade das informações (indicadores) que ele pode trazer para a reflexão dos ecossistemas ou das culturas que se deseja preservar" (DESVALLÉES; MAIRESSE, 2013, p. 70), assumindo a condição de objeto-documento, de evidência material ou imaterial da vasta rede de relações possíveis entre seres vivos, coisas, tempos e lugares.

Sendo assim, ao ser adquirido por uma instituição museológica, cada objeto passa a ser descrito sob duas circunstâncias: sua vida útil antes de fazer parte do museu e depois, quando ganha novos usos e sentidos dentro do espaço de salvaguarda (PADILHA, 2014). Nesse sentido, Ferrez (1994) aponta que as ações de documentação e conservação desenvolvidas nos museus - isto é, aquelas voltadas para a identificação e manutenção da informação contida em um acervo e para o tratamento físico dos objetos - são as bases que impulsionam as outras etapas do ciclo museológico: a pesquisa e a comunicação.

De acordo com Padilha (ibid.), a documentação museológica classifica-se em documentação das práticas administrativas e documentação dos objetos. A documentação das práticas administrativas corresponde "a toda documentação de cunho administrativo produzida pela equipe do museu, que objetiva registrar tudo o que envolve o processo oficial da instituição" (ibid.,p.55). Diz respeito, portanto, a elaboração e gestão de documentos tais como termos de doação, termos de empréstimo, laudos técnicos, fichas de campo, termos de pesquisa, termos de permuta, termos de transferência e termos para transporte de objetos.

2 Os dois primeiros estágios de interpretação do objeto são guiados por um formulário de sessenta questões dividido em nove eixos: características gerais; construção; tecido; etiquetas; uso, alteração e desgaste; material de apoio; reflexos sensoriais; reações pessoais; informações contextuais. 
Já a documentação do objeto volta-se para a "compilação dos dados e do tratamento informacional extraídos de cada objeto adquirido pelo museu" em um movimento que envolve "a seleção, a pesquisa, a interpretação, a organização, o armazenamento, a disseminação e a disponibilização da informação" (ibid.,p.35). Ou seja, trata da transformação dos objetos de "fontes de informação em fontes de pesquisa científica ou em instrumentos de transmissão de conhecimento" (FERREZ, 1994, p.1).

Nesse sentido, Padilha (ibid.) destaca que a atividade de documentação dos objetos envolve desde o levantamento e identificação geral de um acervo/coleção até a análise das características intrínsecas (aspectos físicos) e extrínsecas (aspectos contextuais) de cada objeto. Dessa forma, a fim de garantir a recuperação e o uso da informação de maneira mais eficiente possível, cada objeto incorporado a um acervo museológico deve ser registrado em um Livro Tombo, receber um número de identificação individual, ser classificado de acordo com uma classe, subclasse e um termo (nome), além de ser catalogado a partir de uma ficha individual que compile todas as informações relacionadas a ele.

Para a elaboração de um sistema de documentação eficiente, Cândido (2006, p.36) aponta alguns critérios e medidas básicas a serem seguidos:

\begin{abstract}
Clareza e exatidão no registro dos dados sobre os objetos, sejam textuais, numéricos (códigos de identificação) ou iconográficos; definição dos campos de informação integrantes da base de dados do sistema (código do objeto, seu nome, origem, procedência, datação, material e técnica, autoria, entre outros); obediência a normas e procedimentos pré-definidos, os quais devem estar consolidados em manuais específicos (práticas de controle de entrada e saída de objetos, de registro, classificação, inventário, indexação, etc.); controle de terminologia por meio de vocabulários controlados (listas autorizadas para campos, tais como: nome do objeto, material, técnica, tema, assunto, etc.); elaboração de instrumentos de pesquisa diversos (guias, catálogos, inventários, listagens), visando identificar, classificar, descrever e localizar os objetos dentro do sistema, favorecendo a recuperação rápida e eficiente da informação; previsão de medidas de segurança com relação à manutenção do sistema, garantindo-se a integridade da informação.
\end{abstract}

No que tange a documentação de objetos de vestuário em específico, as diretrizes do Comitê Internacional de Museus e Coleções de Vestuário do ICOM³ (ICOM-COSTU$\mathrm{ME}$ ) orientam que, no ato de aquisição de um objeto, sejam reunidas a maior quantidade de informações possíveis: Qual o nome e endereço do doador, cedente ou vendedor? Que tipo de relação o objeto tinha com o proprietário original? Qual o nome do estilista, marca e/ou fabricante? Existe iconografia disponível relacionada ao objeto? Quando foi adquirido pelo proprietário original? Qual o preço original? Onde foi adquirido? Qual o valor monetário atual? Qual o histórico de uso? Qual a data de confecção? ${ }^{4}$ Como foi usado?

Sobre o processo de catalogação de peças de vestuário, o ICOM-COSTUME (ibid.,p.3) determina que a ficha catalográfica apresente essencialmente as seguintes informações: "número de registro; nome do catalogador e data; data do objeto; dimensões; cor; forma (formato); material; técnica (tecido plano, malha, bordado, feito à mão, feito à máquina) e desenho, croqui ou fotografia (na horizontal ou montados em manequins)". Recomenda, ainda, que a ficha seja duplicada e armazenada em mais de um local e/ou em suportes diferentes.

3 Disponível em <http://network.icom.museum/fileadmin/user_upload/minisites/costume/pdf/guidelines_portuguese.pdf>. Acessado em 21 de julho de 2019.

4 O ICOM COSTUME destaca que a datação por século não é suficiente. Deve-se indicar datas mais precisas. 
Nesse sentido Bickley $(2013)^{5}$ ddestaca alguns pontos importantes que devem ser considerados no ato de catalogação de vestuário: fazer o possível para identificar todos os materiais, partindo dos mais utilizados para os acabamentos e aviamentos; medir cuidadosamente as principais partes da peça; descrever as partes básicas do objeto e depois os detalhes; caracterizar alterações e/ou reparos (caso haja); indicar a localização e o conteúdo de etiquetas, transcrevendo o texto e identificando os símbolos de conservação têxtil; registrar a localização do objeto e mencionar cada vez que ele mudar de lugar, destacando os motivos da mudança e o local para onde foi movido; descrever os contextos em que a peça foi usada.

No que diz respeito ao controle terminológico, COFFEY-WEBB (2016, p.51, tradução nossa) observa que a documentação de coleções de vestuário apresenta dois desafios em particular:

Os termos que se referem as roupas geralmente são difíceis de codificar devido principalmente ao fato de que eles acompanham as tendências da moda e a linguagem do quotidiano. A cada estação, novos nomes são criados para designar objetos e cores muito semelhantes. Por exemplo, nós dizemos "hip-hugger", "dropped-waist" ou "low-slung"? [os três termos significam "cintura baixa" em inglês]. Além disso, as roupas podem ser vestidas de diferentes maneiras. Se um xale é usado como um cachecol, uma faixa ou mesmo um sarongue, ele ainda pode ser considerado um xale ou não? Então, como pode ser chamado?

Considerando essa problemática, o ICOM COSTUME ${ }^{6}$ rrecomenda que a atribuição de termos a um vestuário se dê da seguinte forma: 1 . Termo genérico; 2 . Termo secundário (identificação do modelo e/ou o formato de maneira mais detalhada); 3 . Se necessário, um terceiro item identificando uma variante do termo anterior. Sobre os termos contemporâneos e/ou regionais, indica, ainda, que estes apareçam como segundo, terceiro ou quarto termo entre parênteses, colchete, aspas ou outra convenção estipulada pela instituição a qual o objeto pertence.

Ainda sobre os desafios terminológicos relacionados a documentação de vestuário, vale destacar que o Comitê vem trabalhando, desde 1971, em busca de um "entendimento comum dos termos empregados na descrição do vestuário e seus acessórios" (DRUESEDOW, 2014 apud ICOM/BENARUSH, 2014). Com base nos modos de vestir europeus, o Comitê apresentou, em 1978, a primeira versão de um vocabulário com termos básicos para catalogação de vestuário feminino. Dois anos mais tarde, uma lista de termos relacionados ao vestuário masculino foi divulgada, sendo seguida pela lista de termos de roupas infantis em 1981.

Atualmente, o site do ICOM-COSTUME apresenta versões do vocabulário em inglês, alemão, francês e espanhol ${ }^{7}$. A versão em língua portuguesa foi publicada em 2014, a partir da parceria do ICOM-COSTUME com a Secretaria de Cultura do Rio de Janeiro e projeto do Museu da Moda Brasileira - Casa da Marquesa de Santos (ICOM/ BENARUSH, 2014). A produção brasileira organiza os objetos de vestuário, acessórios, materiais e técnicas em quatorze classes, sendo: Vestuário principal; Vestuário externo/ de proteção; Componentes das roupas; Vestuário íntimo; Vestuário doméstico; Acesrórios de cabeça, tronco e cintura; Acessórios para braços e mãos; Acessórios para pernas e pés; Acessórios portáveis; Acessórios de adorno; Acessórios de cuidado da roupa; Acessórios do fazer roupa; Materiais; Técnicas.

5 In: BICKLEY, Anthea. Clothes tell stories (Documentation). Disponível em: <http://www. clothestellstories.com/index.php/working-with-clothes/documentation>. Acesso em 20 de junho de 2019.

6 Disponível em: <http://network.icom.museum/costume/publications/terminology/>

7 Disponível em: <http://terminology.collectionstrust.org.uk/ICOM-costume/> 


\section{AÇÕES DE DOCUMENTAÇÃO DE VESTUÁRIO NA SEÇÃO MODA DA CO- LEÇÃO AMAZONIANA DE ẢRTE DA UFPA}

Idealizada e curada por Orlando Maneschy, a Coleção Amazoniana de Arte da UFPA foi fundada em 2010 com o propósito de constituir uma coleção de arte contemporânea na/para a UFPA que refletisse o lugar de diferença do artista amazônico "longe dos grandes centros culturais do país" e que fosse "atenta às questões de suma importância para uma região esquecida e oprimida pelo poder público e pela força do capital" (MANESCHY, 2017, p.2).

Depositada no Museu da UFPA e nas Reservas Técnicas do Laboratório de Conservação Preventiva do Patrimônio Móvel da Faculdade de Artes Visuais da UFPA, a Amazoniana divide-se atualmente em três seções: ]Arquivo[, Arte e Moda. A seção Arte envolve cerca de 50 artistas nacionais e internacionais que englobam diversas expressões artísticas tais como pinturas, instalações, vídeos e fotografias. Já o ]Arquivo[ reúne documentos, publicações de artistas, teses, dissertações, além de materiais audiovisuais. Por fim, a seção Moda agrega os objetos doados por André Lima.

A história da Seção Moda começa em 2014 quando o estilista paraense fecha seu ateliê, mantido desde 2002, na capital paulistana e articula a doação de uma parte significativa de seu arquivo pessoal para a Coleção Amazoniana de Arte da UFPA. A seleção dos objetos é feita por André Lima conjuntamente com Yorrana Souza - pesquisadora que, anos antes, desenvolvera sua dissertação voltada para o processo criativo do estilista ${ }^{8}$. Sobre esse processo, Souza (2015) expõe que o critério básico que orientou a escolha do que viria a ser adquirido pela Amazoniana foi o de compor um conjunto de objetos que abrangesse as trajetórias do estilista desde o início de sua carreira nos anos 1980 em Belém até o último desfile da marca André Lima na temporada Verão 2013 da São Paulo Fashion Week.

Diante da diversidade de tipologias dos objetos adquiridos, Orlando Maneschy e Yorrana Maia enxergam a necessidade de formar uma equipe interdisciplinar para que os objetos fossem tratados. Configura-se, assim, o projeto de extensão Ações de curadoria de acervo na Seção Moda da Coleção Amazoniana de Arte da UFPA, por meio de uma parceria entre a Amazoniana, o Bacharelado em Moda da Universidade da Amazônia e o Bacharelado em Museologia da Universidade Federal do Pará. Desse modo, as atividades de documentação da Seção Moda começam em 13 de abril de 2015 com a realização do I Workshop de Conceitos Básicos e Práticos de Curadoria em Reserva Técnica: Seção Moda da Coleção Amazoniana de Arte da UFPA.

Sob coordenação das professoras Marcela Cabral (Museologia/UFPA) e Yorrana Souza (Moda/Unama), o processo de arrolamento se estende até 2016. Para cada vestido criado por André Lima, para cada par de brincos, para cada pasta de imagens de inspiração, o registro no livro tombo, um código de registro, uma etiqueta identificadora, uma ficha a ser preenchida e algumas fotografias. Diante de cada objeto, algumas interrogações: Do que se trata? Quais os materiais e as técnicas utilizadas? Qual o estado de conservação? Apresenta fungos, traças ou larvas? Perdas de material? Há alguma indicação da data de produção?

O arrolamento dos objetos de vestuário, em específico, foi acompanhado por uma ficha de diagnóstico preliminar com os seguintes campos: número de registro do objeto;

8 Ver referências. 
título; nome comum do objeto; descrição física; imagens; estado de conservação [Bom, regular ou ruim; Manchas? Descosturas? Rasgos? Pragas? Perdas de materiais?]; observações; responsáveis técnicos (CABRAL, SANTOS, 2016).

Ao final do processo de arrolamento dos objetos doados, foram contabilizados 1050 objetos /conjuntos de objetos, sendo: 256 objetos de vestuário; 56 amostras de estampa e tecidos; 239 acessórios; 382 itens de acervo documental e 117 aviamentos. A partir daí, criou-se um sistema de codificação para a identificação individual dos objetos. Formado por quatro partes, o sistema concebido alterna letras, algarismos romanos e indo arábicos, segundo a lógica: 'RTM - abreviação de Reserva Técnica de Museologia; AL - abreviação de André Lima; I, II, III, IV ou V - indica a categoria do acervo (I- Vestuário/ II - Amostras de estampa e tecidos/ III - Acessórios/ IV - Acervo documental/ VAviamentos); numeração sequencial dos objetos pertencentes a uma mesma categoria. Em caso de desdobramento, uma quinta parte é adicionada: letras minúsculas indicando a quantidade de itens do conjunto $(a ; b ; c . .$.$) . Assim, para registrar um par de brincos, por$ exemplo, procede-se da seguinte maneira: 'RTM.AL.III.001.a' e 'RTM.AL.III.001.b'.

Em 2017, após a conclusão desse reconhecimento inicial e da tomada de medidas básicas de conservação preventiva e curativa, elaborou-se o inventário da coleção para, em seguida, ser dado início ao processo de catalogação. Tendo em vista a complexidade envolvida em cada categoria da Seção Moda, decidiu-se priorizar a catalogação dos acervos documental e de vestuário. Sendo assim, Sammya Santos e Bernardo Conceição - na época, graduandos em Museologia da UFPA - dedicaram seus trabalhos de conclusão de curso para a organização documental dessas duas categorias.

Assim, com objetivo de constituir um sistema documental que facilitasse a interoperabilidade com outras instituições/coleções que salvaguardam tipologias semelhantes, a equipe de trabalho da Seção Moda optou por utilizar as publicações Thesaurus para acervos museológicos (FERREZ; BIANCHINI, 1987)9 e Termos básicos para a catalogação de vestuário (ICOM COSTUME/BENARUSH, 2014) como bases classificatórias e terminológicas. Dessa forma, Santos (2017) fundamentou-se nessas publicações para elaborar o esquema classificatório e ficha catalográfica da categoria Vestuário.

Conforme observa-se na tabela abaixo, o esquema classificatório desenvolvido para os objetos de vestuário adotou a classificação e subclassificação engendrada pelo Thesaurus para acervos museológicos (FERREZ, BIANCHINI, 1987) enquanto a padronização dos termos de identificação dos objetos de vestuário se deu pela publicação Termos básicos para a catalogação de vestuário (ICOM COSTUME/BENARUSH, 2014).

Tabela 1 - Esquema classificatório da categoria (I) Vestuário.

\begin{tabular}{|c|l|l|}
\hline Classe & Subclasse & \multicolumn{1}{c|}{ Termos (nomes dos objetos) } \\
\hline $\begin{array}{c}\text { Objetos } \\
\text { pessoais }\end{array}$ & Vestuário & $\begin{array}{l}\text { Bermuda, blusa, calça, camisa, macacão, short, saia, vestido, blazer, bolero, } \\
\text { capa, casaco, colete, jaqueta, paletó, suéter, calcinha, cinta-liga, combina- } \\
\text { ção, corpete, sutiã, estola, xale, maiô e biquíni. }\end{array}$ \\
\hline
\end{tabular}

Fonte: Autora com base em Santos (2017).

Com relação à ficha catalográfica de vestuário, Santos (ibid.) propôs 35 campos de preenchimento divididos em quatro partes, conforme a tabela abaixo:

9 Idealizado por Helena Ferrez e Maria Helena Bianchini, o Thesaurus para acervos museológicos (1987) objetivava de início abranger o universo dos objetos do Museu Histórico Nacional (MHN), porém acabou se tornando uma obra de referência largamente utilizada pelos museus brasileiros (PADILHA, 2014). 
Tabela 2 - Estrutura da ficha catalográfica de vestuário.

\begin{tabular}{|c|l|}
\hline Partes & \multicolumn{1}{|c|}{ Campos de preenchimento } \\
\hline (1) Identificação do objeto & $\begin{array}{l}\text { Coleção; número de registro; termo; classe; subclasse; título; au- } \\
\text { tor; data; data de aquisição; origem; procedência; material; técni- } \\
\text { cas; modo de aquisição; dimensões [altura; largura]; localização; } \\
\text { imagem do objeto; descrição do objeto; dados fotográficos. }\end{array}$ \\
\hline (2) Análise de conservação & $\begin{array}{l}\text { Conservação [bom; ruim; regular ou péssimo]; perda de material } \\
\text { [sim; não]; intervenções [sim; não]; recomendações; descrição do } \\
\text { diagnóstico de conservação. }\end{array}$ \\
\hline (3) Análise histórica & $\begin{array}{l}\text { Dados históricos; publicações; características iconográficas; carac- } \\
\text { terísticas estilísticas; referências arquivísticas e bibliográficas }\end{array}$ \\
\hline (4) Dados de preenchimento & Responsável pelo preenchimento/ data; revisor/ data \\
\hline
\end{tabular}

Fonte: Autora com base em Santos (2017).

\section{RTM.AL.I.17: PENSANDO A CLASSIFICAÇÃO DE UMA ROUPA HÍBRIDA AÇÕES DE DOCUMENTAÇÃO DE VESTUÁRIO NA SEÇÃO MODA DA COLE- ÇẤO AMAZONIANA DE ARTE DA UFPA}

Entre os 1050 itens/conjuntos de itens doados pelo estilista paraense André Lima à Coleção Amazoniana de Arte da UFPA, o objeto de nosso estudo foi o $17^{\circ}$ a ser arrolado na categoria de vestuário, conforme consta em seu registro 'RTM.AL.I.17'. Em um primeiro contato com o objeto, é possível perceber a combinação entre as estruturas de construção de vestuário aberto e fechado. A parte da frente da peça é constituída por três elementos: corpete, saia e calcinha costurada na barra da saia. Já a costa, é composta por duas partes: um corpete branco e uma calcinha preta.

Figura 1 - Frente e costa do objeto 'RTM.AL.I.17'

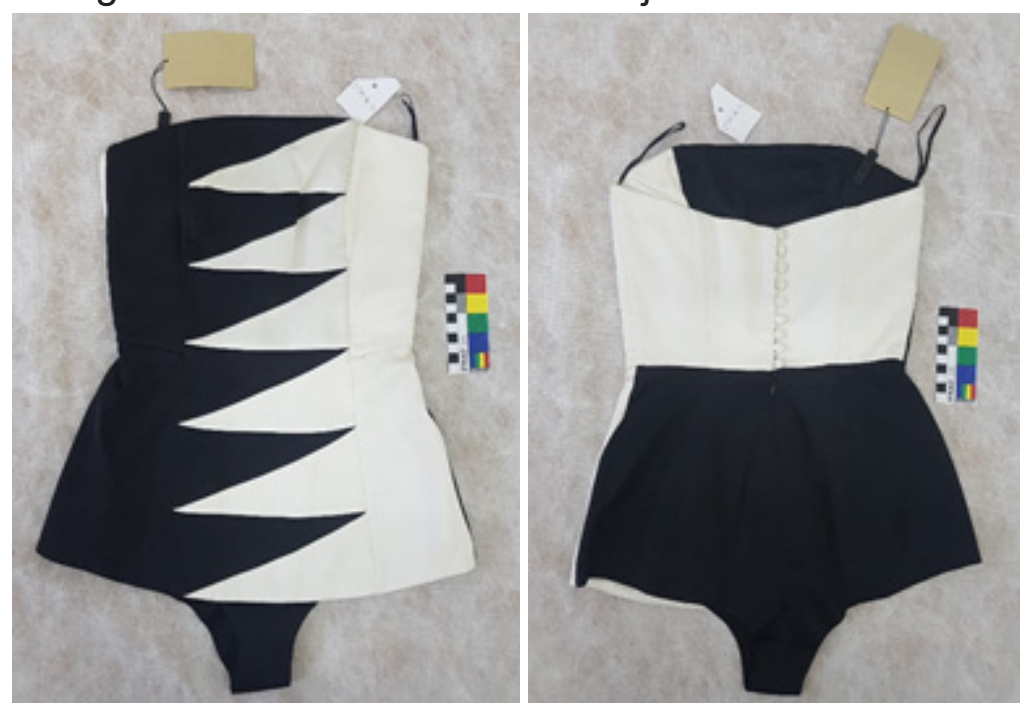

Fonte: Dias, 2018.

O objeto apresenta decote do tipo tomara que caia e recortes geométricos que formam no centro-frente um padrão de doze triângulos retângulos que se alternam em preto e branco. Quatro barbatanas dão sustentação ao corpete: duas na frente e duas nas costas. Nove botões encapados e um zíper invisível no centro-costas fecham a peça. Observamos, também, atrelada ao objeto, uma tag de papel com o logotipo da marca 'André Lima', um adesivo com um código de barra e a indicação de que se trata de uma peça de desfile (tamanho 38).

No avesso, a peça apresenta três etiquetas. A primeira, costurada próximo ao decote das costas, identifica a marca (lê-se: "André Lima"). A segunda, localizada na 
lateral esquerda do corpete, apresenta dados referentes ao processo de confecção, tiragem e tamanho. Lê-se: "Esta é uma peça de edição limitada e produzida artesanalmente. Seguir corretamente as instruções de lavagem para sua perfeita conservação/ 38". A terceira, também na lateral do corpete, exibe os dados jurídicos da marca 'André Lima', a composição têxtil da peça, um código de referência, a origem, além de sete símbolos que indicam a melhor maneira de conservar o objeto. Lê-se: "IMPÉRIO; CONFECÇÕES LTDA-ME; CNPJ: 03.998.818/0001-33; Tecido: 100\% seda; Forro: 100\% poliéster; Ref: 2225470; Não deixar de molho; FEITO NO BRASIL". Os sete símbolos de conservação têxtil expostos na etiqueta indicam: não fazer lavagem doméstica a máquina ou manual; não alvejar; não secar em tambor; passar o ferro até $110 \circ C$, risco a "vapor" ou "prensa"; limpeza a seco profissional $P$, suave ${ }^{10}$.

Figura 2 - Tag e etiquetas atreladas ao objeto RTM.AL.I.17.
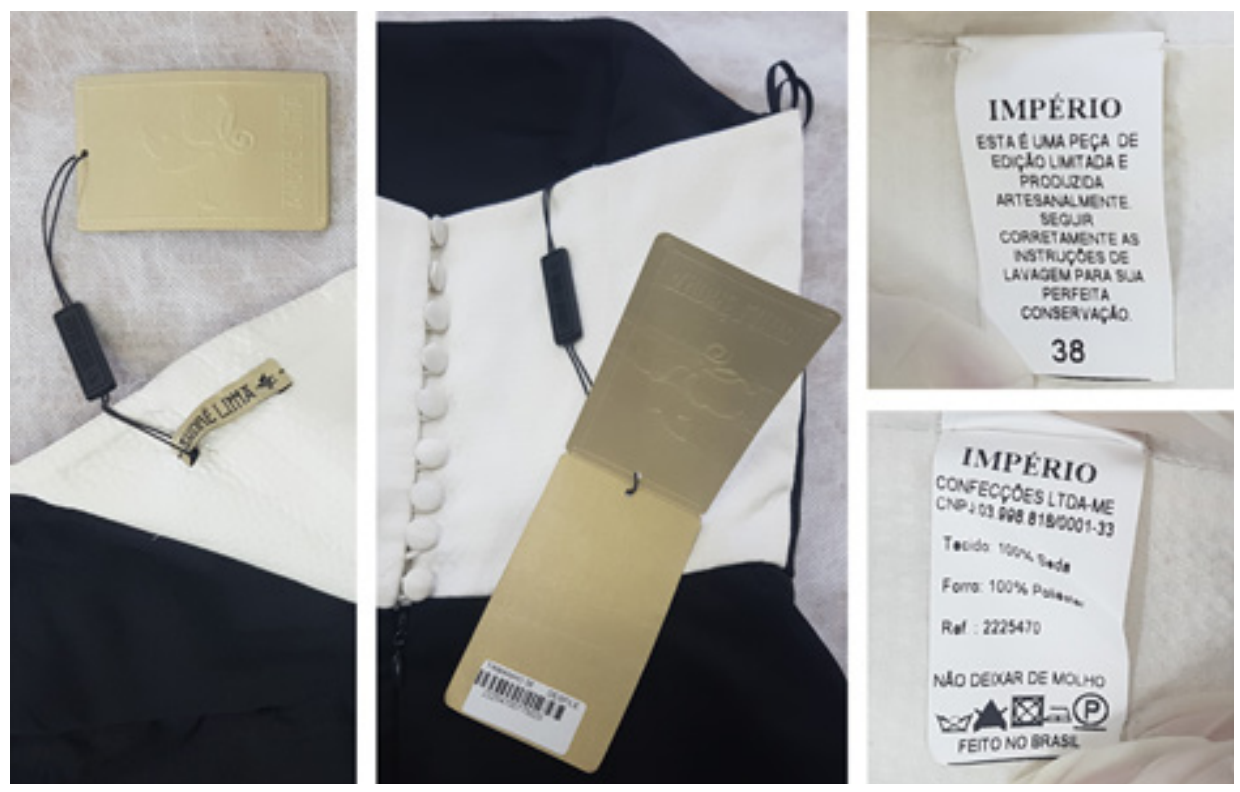

Fonte: Dias, 2018.

Comparando os dados apresentados nas etiquetas sobre a composição têxtil com as características físicas da peça, percebemos uma discordância. Observa-se que tanto o direito quanto o forro do objeto foram confeccionados com o mesmo material. Possivelmente, o poliéster indicado em uma das etiquetas como material do forro corresponde a dois tipos de entretela que reforçam a peça: entretela termocolante (aderida ao direito da peça) e entretela costurável (entre as camadas do direito e do forro) ${ }^{11}$.

Após esse reconhecimento inicial do objeto, consultamos o livro André Lima da Coleção Moda Brasileira (2008), além de vídeos e fotografias ${ }^{12}$ dos desfiles realizados pela marca, a fim de saber quando a peça havia sido feita. Verificou-se, assim, a partir de fotografias do desfile ${ }^{13}$ realizado em 21 de junho de 2018, na São Paulo Fashion Week,

\footnotetext{
10 Os símbolos de conservação têxtil que aparecem na etiqueta foram identificados a partir da publicação Normalização: Caminho da qualidade na confecção (2012), elaborada pela Associação Brasileira de Normas Técnicas (ABNT) e pelo Serviço Brasileiro De Apoio Às Micro E Pequenas Empresas. Ver referências.

11 Foi possível perceber que havia dois tipos de entretela empregados na peça através de uma área de descostura de cerca de $7 \mathrm{~cm}$, localizada na junção da calcinha à barra da saia no avesso da parte da frente do objeto.

12 Nesse momento da pesquisa, foram verificadas as fotografias que compõem a Seção Moda da Amazoniana, além de vídeos e fotografias dos desfiles do estilista disponíveis no arquivo do Portal UOL. Links: <https://ffw.uol.com.br/desfiles/andre-lima/>; <https://www.uol.com.br/mov/busca/?q=andr \%C3\%A9\%20lima\%20desfile.>. Acesso em 29 de junho de 2019.

13 Fotografias disponíveis em <https://ffw.uol.com.br/desfiles/sao-paulo/verao-2009-rtw/andre-lima/128 8/colecao/thumbs/>. Acesso em 27 de junho de 2019.
} 
que um exemplar da peça analisada compunha o look 5 da coleção ${ }^{14}$ Verão 2009 André Lima. Notou-se, ainda, no $10^{\circ}$ look, a presença de uma peça de estrutura semelhante.

Figura 3 - Looks 5 e 10 do desfile da Coleção Verão 2009 André Lima, 2008.

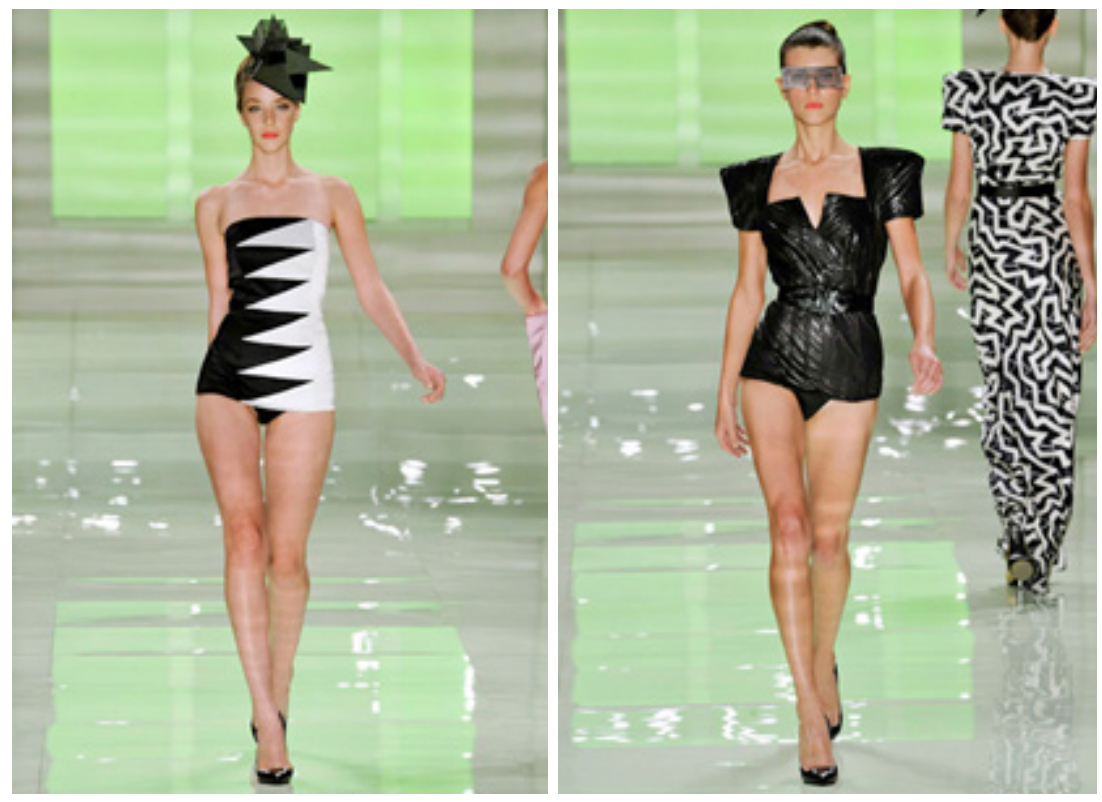

Fonte: FFW' ${ }^{15}$.

Entre os 23 looks desfilados, observou-se uma coleção de estilo maximalista pautada por sucessivos exercícios de decomposição geométrica tais como sobreposições de pregas, laços gigantes, dobraduras e pontas que saltam do corpo das peças. Em termos de silhueta, percebeu-se o predomínio da cintura marcada, de mangas estruturadas e volumosas em vestidos de base reta - elementos que remetem ao power dressing dos anos 1980 (MACKENZIE, 2010; HAYE;MENDES, 1999). Um outro aspecto que se destacou na coleção Verão 2009 André Lima foi a forte presença da combinação preto-branco nas roupas. O jogo cromático apareceu, não só no objeto 'RTM.AL.I.17', mas também em outras seis peças apresentadas no desfile.

\footnotetext{
14 Vale destacar que, para a moda, 'coleção' se refere a uma reunião de peças de vestuário e/ou acessórios que guardam certos aspectos em comum organizadas segundo critérios estabelecidos por um designer/uma marca (SEIVEWRIGHT, 2015, 172). Já em termos museológicos, a palavra coleção diz respeito a "um conjunto de objetos materiais ou imateriais (...) que um indivíduo, ou um estabelecimento, se responsabilizou por reunir, classificar, selecionar e conservar em um contexto seguro e que, com frequência, é comunicada a um público mais ou menos vasto" (DESVALLÉES; MAIRESSE, 2013, p.32).

15 Disponível em: <https://ffw.uol.com.br/desfiles/sao-paulo/verao-2009-rtw/andre-lima/1288/colecao/th umbs/>. Acessado em 29 de junho de 2019.
} 
Figura 4 - Looks 3, 13, 14 e 3 do desfile Verão 2009 André Lima.
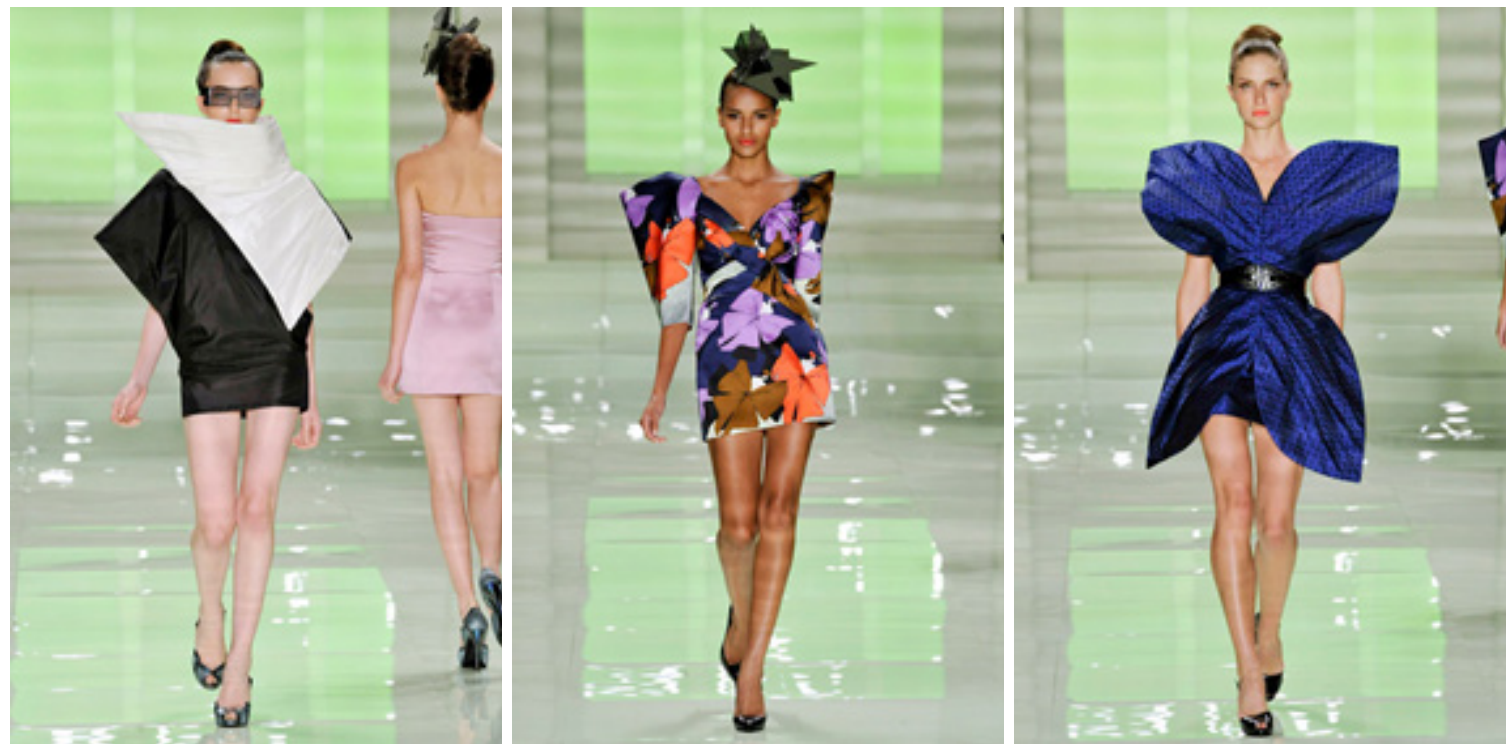

Fonte: $\mathrm{FFW}^{16}$.

Ao expandirmos o olhar para outras coleções concebidas por André Lima, percebemos que esse padrão positivo-negativo é recorrente em suas criações. Seja em estampas e/ou em recortes, encontramos a utilização desse jogo visual em coleções como as das temporadas Inverno 2004, Verão 2010 e 2013. Já em termos conceituais, o padrão aparece, por exemplo, no desfile 'Um desejo só não basta' (Verão 2005) por meio de referência ao princípio taoísta Yin-Yang.

Figura 5 - Combinações preto-branco nas coleções Inverno 2004, Verão 2010 e 2013 da marca André Lima.
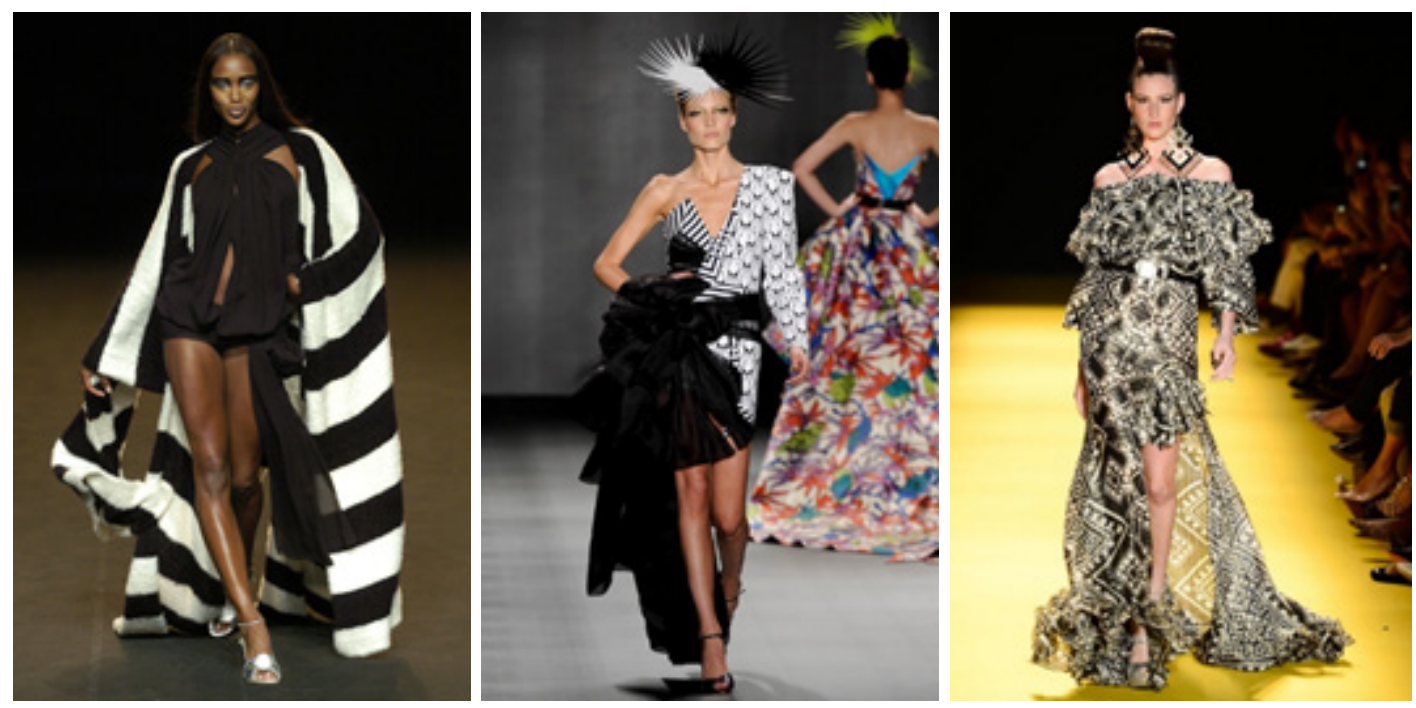

Fonte: FFW' ${ }^{17}$.

De volta ao espaço da reserva técnica da Amazoniana, olhamos para os recortes geométricos do objeto 'RTM.AL.I.17' e enxergamos a lógica do Yin-Yang: a dualidade presente em todos os níveis de existência; o eterno conflito de forças opostas e complementares; a ideia de que ao mesmo tempo em que há um ponto preto no branco, há um

16 Disponível em <https://ffw.uol.com.br/desfiles/sao-paulo/verao-2009-rtw/andre-lima/1288/colecao/th umbs/>. Acessado em 29 de junho de 2019.

17 Disponível em <http://ffw.uol.com.br/desfiles/sao-paulo/andre-lima/>. Acessado em 29 de junho de 2019. 
ponto branco no preto. Vemos um objeto que aponta, a partir de sua estrutura híbrida e do jogo visual produzido pelos seus recortes, para uma lógica que sugere o uso da conjunção "e" ao invés de "ou".

Com esse pensamento em mente, buscamos outros objetos da coleção Verão 2009 André Lima constituintes da Seção Moda da Amazoniana. Encontramos no clipping do mês de setembro de 2008, algumas páginas da edição 473 da revista IstoÉ Gente, nas quais a atriz Grazielli Massafera figura em um ensaio fotográfico, vestida com um exemplar da peça estudada. No ensaio, a roupa é identificada como 'maiô-corselet'.

Figura 6 - Páginas da Revista ISTOÉ Gente, Ano X, No473, 29.09.2008.

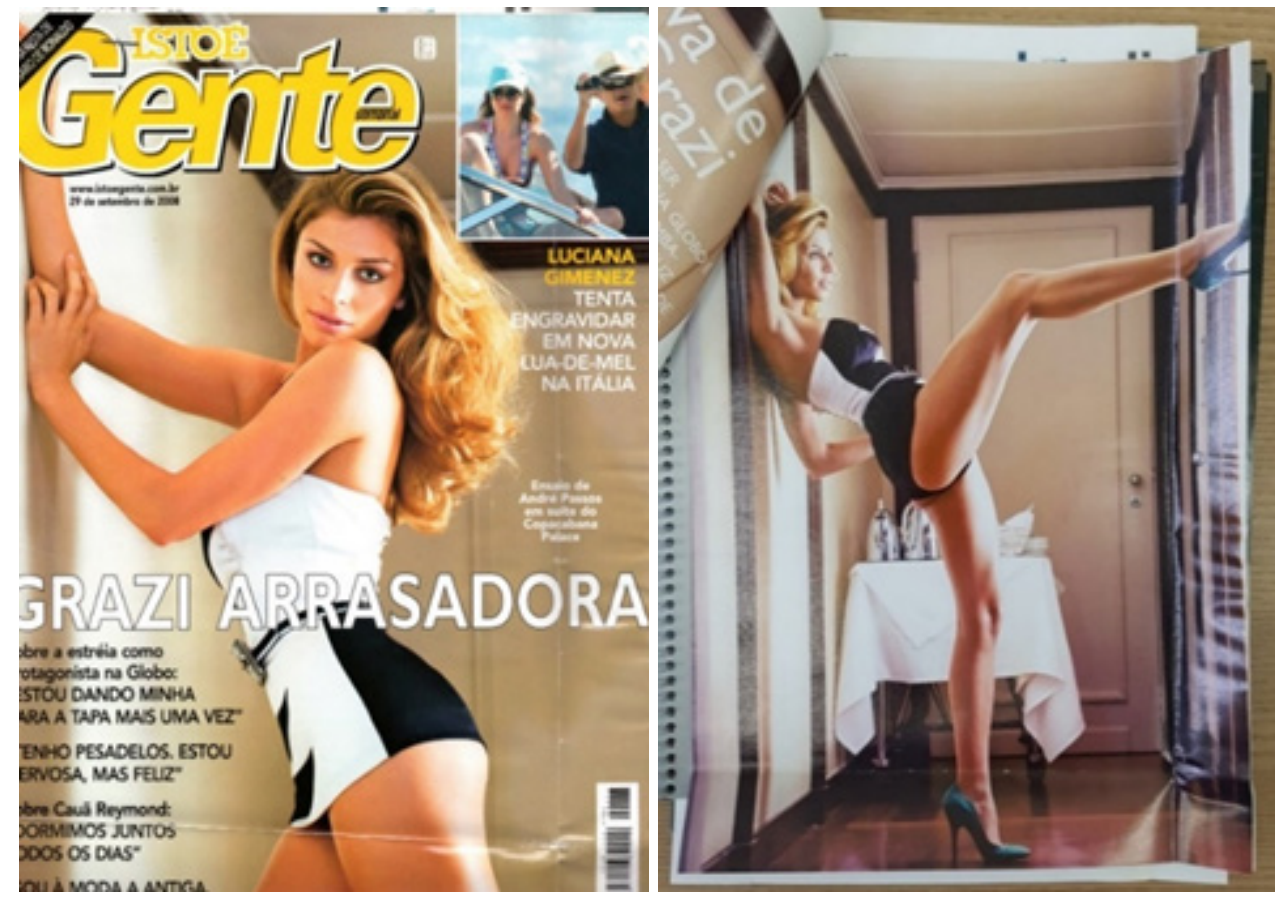

Fonte: Seção Moda da Coleção Amazoniana de Arte da UFPA (RTM.AL.IV.56).

Mais adiante, temos acesso ao clipping referente ao mês de outubro de 2008. Em um editorial de moda da revista de moda L'officiel - $B R$, aparece a peça que compôs o look 10 do desfile da coleção Verão 2009 e que apresenta estrutura semelhante ao objeto 'RTM.AL.I.17'. No editorial, tal peça é descrita como um 'maiô'. 
Figura 7 - Editorial de moda com peça integrante do look 10 do desfile Verão 2009 André

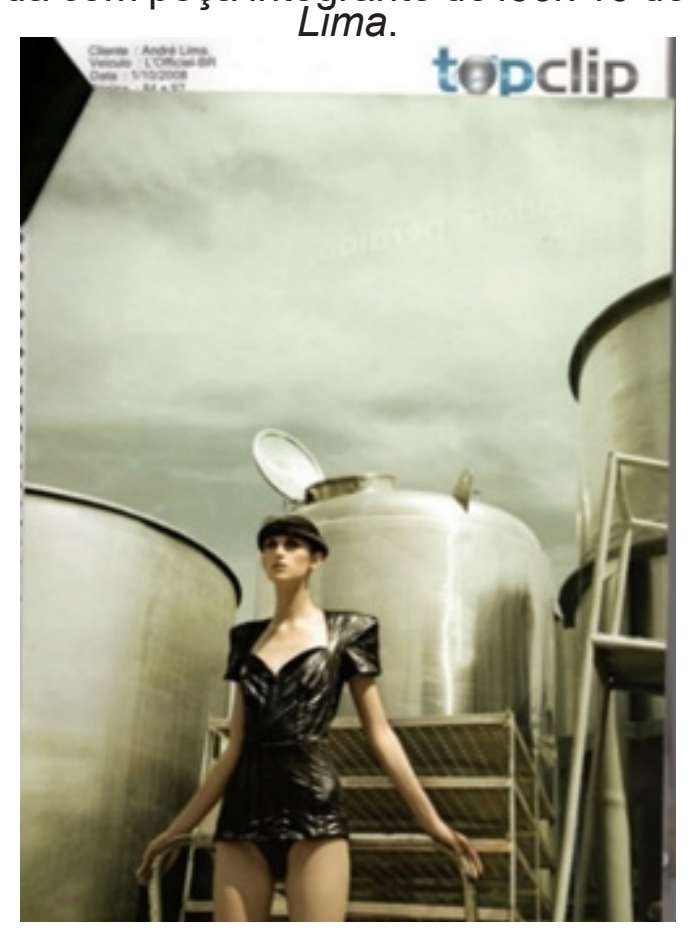

Fonte: FFW ${ }^{18}$.

Embora as publicações não tenham o compromisso de seguir uma terminologia controlada, nota-se uma divergência quanto aos termos atribuídos a peças de construção semelhante. Enquanto a primeira sugere um nome que evidencia a mistura entre duas peças (maiô-corselet), a segunda emprega um único termo (maiô). Segundo Catellani (2003), corselet se refere a um corpete justo que vai até a cintura, utilizado comumente na moda íntima feminina para modelar o corpo. Já o maiô, de acordo com a publicação Termos básicos para a catalogação de vestuário (ICOM/BENARUSH, 2014, p.11), é uma "peça de banho feminina única, aderente ao corpo, com ou sem alças".

Sendo assim, notamos que os termos empregados pelas revistas desconsideram o saiote que cobre os quadris na parte da frente do objeto analisado. Apesar disso, é possível enxergar que a peça estudada guarda relações estruturais com o maiô, com o corselet e com a saia. Nesse sentido, apesar de seu material não ser apropriado para banho, o objeto 'RTM.AL.I.17' nos remete às transformações das roupas de banho ao longo da história e, sobretudo, aos primeiros modelos de peça única criados e difundidos ao longo da primeira metade do século XX.

Callan (2007) expõe que, até o final do século XIX, as roupas de banho eram compostas por duas peças: um tipo de túnica comprida com mangas e um knickers (calção folgado), que, combinadas, cobriam o corpo quase que por inteiro. A autora relata que os primeiros trajes de banho inteiriços começam a aparecer na virada do século XIX para o $X X$, sendo utilizados inicialmente somente por homens.

Em 1907, a nadadora australiana Annette Kellerman enfrenta a sociedade da época e introduz o uso da peça única pelas mulheres. Anos depois, a marca americana Jantzen lança seus trajes de banho inteiriços para mulheres e a peça começa a se popularizar. Delgado (2016) relata que essas peças costumavam ser formadas por uma espécie de maiô com um short interno ou com um saiote sobreposto, que ocultava o entrepernas - um modelo muito semelhante ao objeto 'RTM.AL.I.17'.

18 Disponível em <http://ffw.uol.com.br/desfiles/sao-paulo/andre-lima/>. Acessado em 29 de junho de 2019. 
Figura 8 - Traje de banho da marca Jantzen, c. anos 1950.

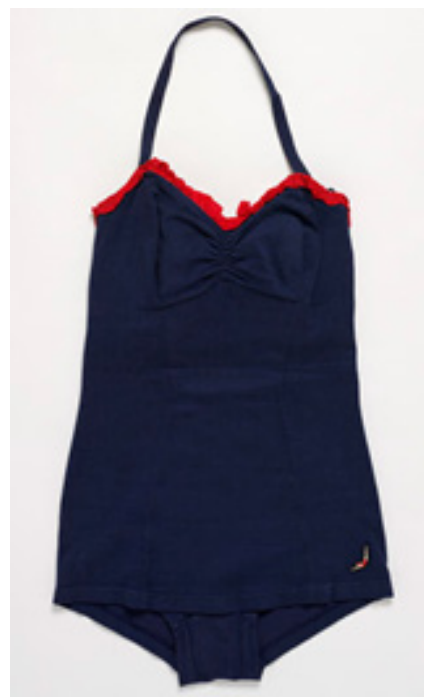

Fonte: Victoria \& Albert Museum. ${ }^{19}$

Diante, portanto, do estudo das características intrínsecas do objeto 'RTM.AL.I.17', da investigação das narrativas vestíveis criadas por André Lima na coleção Verão 2009, da análise das nomenclaturas empregadas pelos ensaios fotográficos encontrados na Amazoniana e da percepção da semelhança do objeto com os trajes de banho criados no início do século XX, indicamos dois caminhos classificatórios para a peça: 'maiô-saia' e 'maiô-vestido'.

Apesar das orientações do ICOM Costume sobre terminologia ${ }^{20}$ não citarem explicitamente a possibilidade de atribuição de um termo híbrido a um objeto, nota-se que a publicação Termos básicos para a catalogação de vestuário traz termos como 'vestido-avental', 'vestido-casaco' e 'saia semi-godê' (2014, p.11-12). Enxergamos, dessa maneira, uma estratégia de classificação para o objeto 'RTM.AL.I.17' que respeita tanto suas especificidades materiais e conceituais quanto a lógica de documentação da Seção Moda da Coleção Amazoniana de Arte da UFPA.

Baseados, assim, nas definições estabelecidas pela publicação Termos básicos para a catalogação de vestuário (ibid., p.11), consideramos que o objeto 'RTM.AL.I.17' pode ser visto como uma mistura entre um maiô e uma saia - "peça de forma e comprimentos variados, cobrindo da cintura para baixo" (ibid.,11) -, gerando o termo maiô-'saia'. Ou, ainda, como um vestido - "peça de forma e comprimento variáveis, que pode constituir-se de uma só peça inteiriça ou dois elementos que se integram, um cobrindo a parte superior do corpo, exceto a cabeça, e outro, das ancas para baixo" (ibid., p.12) - de comprimento micro, que também expõe a estrutura de um maiô, originando o termo 'vestido-maiô'.

Comparando as duas possibilidades classificatórias, compreendemos que o termo 'vestido-maiô' contempla as características do objeto 'RTM.AL.I.17' de uma maneira ainda mais específica, já que os materiais empregados na peça não são apropriados para uso na água. Retornando ao contexto do desfile da coleção Verão 2009 André Lima, consideramos, ainda, que o estilista procurou embaralhar as noções de roupa de praia e roupa de festa.

19 Disponível em <http://collections.vam.ac.uk/item/011718/bathing-costume-jantzen/\#>. Acessado em 21 de junho de 2019.

20 Disponível em: <http://network.icom.museum/costume/publications/terminology/>. Acesso em 21 de junho de 2019. 


\section{CONSIDERAÇÕES FINAIS}

No início dessa trajetória, tínhamos como objetivos fundamentais discutir e propor alternativas de classificação do objeto 'RTM.AL.I.17' no âmbito da lógica documental da Coleção Amazoniana de Arte da UFPA. Sendo assim, buscamos, em primeiro lugar, relacionar as principais demandas envolvidas na documentação de coleções museológicas de vestuário, desde o processo de aquisição até a catalogação dos objetos. Em seguida, expusemos as ações de documentação de vestuário desenvolvidas na Seção Moda da Amazoniana desde a aquisição dos objetos advindos do ateliê do estilista André Lima. Por fim, chegamos ao momento crucial do estudo quando analisamos o objeto 'RTM. AL.I.17' e sugerimos a utilização do termo 'vestido-maiô'.

Assim, por meio do método interpretativo de objetos de moda idealizado por Mida e Kim (2015), foi possível delinear um caminho transversal de pesquisa marcado por idas e vindas, aproximações e afastamentos entre o objeto estudado, os manuais de terminologia, as histórias da moda e os universos imaginados por André Lima em seus desfiles e coleções. Esse movimento ziguezagueante nos permitiu interrogar o objeto de diversas maneiras e confrontar visões de diferentes disciplinas, fornecendo, dessa maneira, uma percepção expandida das questões que instauraram o estudo.

Considerando que o processo de catalogação é contínuo e que todo processo de classificação guarda algo de arbitrário, procuramos, a partir do termo classificatório indicado, estabelecer um certo equilíbrio entre a lógica dos manuais de terminologia adotados atualmente pela Seção Moda, a estrutura da peça e as propostas de André Lima para a coleção Verão 2009.

Ao ampliarmos o olhar para outras coleções idealizadas pelo estilista, verificamos que a utilização do padrão positivo-negativo era recorrente. A referência ao Yin-yang na coleção Verão 2005, nos fez pensar no princípio taoísta como um possível eixo norteador do trabalho criativo do estilista André Lima - questão a ser trabalhada em pesquisas futuras. Com relação ao objeto 'RTM.AL.I.17', concluímos que, tanto estruturalmente quanto conceitualmente, a peça traz consigo uma lógica que não divide, mas multiplica, uma lógica que não separa, mas conjuga.

\section{REFERÊNCIAS}

ASSOCIAÇÃO BRASILEIRA DE NORMAS TÉCNICAS; SERVIÇO BRASILEIRO DE APOIO ÀS MICRO E PEQUENAS EMPRESAS. Normalização: Çaminho da qualidade na confecção. Rio de Janeiro: ABNT; SEBRAE, 2012. Disponível em <http://portalmpe. abnt.org.br/bibliotecadearquivos/>. Acessado em 23 de junho de 2019.

BICKLEY, Anthea. Documentation. In: ICOM COSTUME COMITEE (org.). Clothes tell stories: working with costumes in museums, 2013. Disponível em: <http://ww w.clothestellstories.com/index.php/working-with-clothes/documentation>. Acesso em 20 de junho de 2017.

CABRAL, Marcela G.; SANTOS, Sammya D. P. Moda, patrimônio e curadoria de acervos museológicos: uma perspectiva da Seção Moda da Coleção Amazoniana de Arte. In: Anais do $6^{\circ}$ Seminário Moda documenta e $3^{\circ}$ Congresso Internacional de Memória, Design e Moda. Universidade Federal do Paraná, Curitiba, 2016.

CALLAN, Georgina O'Hara. Enciclopédia da moda de 1840 à década de 1990. São Paulo: Companhia das Letras, 2007. 
CÂNDIDO, Maria Inez. Documentação Museológica. In: Caderno de diretrizes museológicas 1. Brasília: Ministério da Cultura / Instituto do Patrimônio Histórico e Artístico Nacional/ Departamento de Museus e Centros Culturais, Belo Horizonte: Secretaria de Estado da Cultura/ Superintendência de Museus, 2006. $2^{\circ}$ Edição. p.31-90.

CATELLANI, Regina M. Moda Ilustrada de A a Z. Barueri, SP: Manole, 2003.

COFFEY-WEBB, Louise. Managing Costume Collections: an essential primer. Texas Tech University Press, 2016.

DELGADO, Valéria. Senai Cenário: Praia. Rio de Janeiro: Federação das Indústrias do Estado do Rio de Janeiro/Sistema FIRJAN, 2016.

DESVALLÉES, André; MAIRESSE, François (editores). Conceitos-chave de museologia. São Paulo: Comitê Brasileiro do Conselho Internacional de Museus: Pinacoteca do Estado de São Paulo: Secretaria de Estado da Cultura, 2013.

DIAS, Susanne P. Documentação museológica de moda contemporânea: catalogação de roupas desobedientes de André Lima na Coleção Amazoniana de Arte da UFPA. Programa de Pós-graduação em Comunicação, Linguagens e Cultura, Universidade da Amazônia, 2018.

FERREZ, H. D.; BIANCHINI, M. H. S. Thesaurus para acervos museológicos. Rio de Janeiro: MINC/ SPHAN/PróMemória, 1987. (v.1; v.2)

FERREZ, Helena D. Documentação museológica: teoria para uma boa prática. In: Cadernos de Ensaio n. 2, Estudos de Museologia, Rio de Janeiro: MinC / IPHAN, p. 64-74, 1994.

HAYE, Amy de la; MENDES, Valerie. 20th century fashion. London: Thames \& Hudson, 1999.

ICOM COSTUME. Diretrizes do Comitê de Indumentária - ICOM. Versão em português. Rio de Janeiro: Governo do Rio de Janeiro / Instituto Zuzu Angel. Sem data. 8p. Disponível em <http://network.icom.museum/fileadminuser_upload/minis ites/costume/ pdf/guidelines_portuguese.pdf>. Acessado em 21 de julho de 2019.

ICOMCOSTUME; BENARUSH, Michelle. Termos básicos para a catalogação de vestuário. Tradução de Michelle Benarush. Rio de janeiro: Casa da Marquesa de Santos - Museu da Moda Brasileira, 2014.

MACKENZIE, Mairi. Ismos: para entender a moda. São Paulo: Globo, 2010.

MANESCHY, Orlando. Coleção Amazoniana de Arte da Universidade Federal do Pará, desafios, processos e subversões para um campo alargado e decolonialista. In: Anais do $3^{\circ}$ Seminário Brasileiro de Museologia. Belém: Universidade Federal do Pará, 2017.

MIDA, Ingrid; KIM, Alexandra. The dress detective: a practical guide to object-based research in fashion. London/New York: Bloomsbury Publishing Plc, 2015.

PADILHA, Renata C. Documentação museológica e gestão de acervo. Florianópolis: FCC, 2014.

QUEIROZ, João R.; BOTELHO, Reinaldo (orgs.). André Lima (Coleção Moda Brasileira). São Paulo: Cosac Naify,2008.

SANTOS, Sammya D. P. D. Documentação de acervos museológicos: um estudo de caso do acervo de vestuário do estilista André Lima na Seção Moda da Coleção Amazoniana de Arte da UFPA. Trabalho de conclusão de curso - Ủniversidade Federal do Pará, Bacharelado em Museologia, 2017. 
SEIVEWRIGHT, Simon. Fundamentos do design de moda: pesquisa e design. $2^{\mathrm{a}}$ ed. Porto Alegre: Bookman, 2015.

SOUZA, Yorrana P. M. Da roupa ao processo: reflexões sobre o acervo do estilista paraense André Lima. Congresso Internacional de História, 7., 2015, Maringá. In: Anais do VII Congresso Internacional de História. Maringá: Universidade Estadual de Maringá, 2015. P.2071-2083. Disponível em <http://www.cih.uem.br/anais/2015/ trabalhos/1410. pdf>. Acesso em 25 maio/2019.

SOUZA, Yorrana P. M. Cartografia de si: territórios particulares e compartilhados do processo de criação do estilista André Lima. Dissertação - Universidade da Amazônia, Programa de Pós-graduação em Comunicação, Linguagens e Cultura, 2013.

TERMINOLOGY. International Comittee for Museums and Collections of Costume, [20??]. Disponível em: <http://network.icom.museum/costume/publications /terminology/>. Acessado em 21 de junho de 2019

Recebido em: 14/08/2019

Aceito em: 25/08/2019

DOI: http://dx.doi.org/10.5965/25944630332019080 